\title{
Integration of 3D-seismic and petrophysical analysis with rock physics analysis in the characterization of SOKAB field, Niger delta, Nigeria
}

\author{
S. S. Bodunde ${ }^{1}$ (D) P. A. Enikanselu ${ }^{1}$
}

Received: 7 March 2018 / Accepted: 5 October 2018 / Published online: 12 October 2018

(c) The Author(s) 2018

\begin{abstract}
Compartmentalization of reservoirs and technical failures experienced in data acquisition, processing and interpretation, without doubt, hinder the effective characterization of reservoirs. In this research, to ensure accuracy, three methods were integrated to characterize reservoirs in SOKAB field. Petrophysical analysis, seismic interpretation, and modeling, and rock physics analysis were utilized. Its objectives were: to develop a template to facilitate improvements in future reservoir characterization research works and producibility determination; to utilize rock physics models to quality check the seismic results and to properly define the pore connectivity of the reservoirs, and to locate the best productive zones for future wells in the field. Forty-three faults were mapped and this included five major faults. Two hydrocarbon bearing sand units (A \& B) were correlated across five wells. Structural maps were generated for both reservoirs from which majorly fault assisted and dependent closures were observed. The petrophysical analysis indicated that the reservoirs have good pore interconnectivity (Average $\Phi_{\text {effective }}=23 \% \& 22 \%$ and $K_{\text {average }}=1754 \mathrm{md} \& 2295 \mathrm{md}$ ). The seismic interpretation and modeling alongside the petrophysical analysis were then quality checked via qualitative rock physics analysis. From the $K_{\text {dry }} /$ Porosity plot, the sands were generally observed to lie within the lower Reuss and upper Voigt bound which indicates a low level of compaction. From the velocity-porosity cross plot, it was revealed that the lower portions of the reservoirs were poorly cemented and this could hinder their producibility.
\end{abstract}

Keywords Reservoir characterization · Lower Reuss $\cdot$ Upper Voigt $\cdot$ Petrophysics $\cdot$ Rock physics $\cdot$ Cross-plots

\section{Introduction}

In economically unstable times as this in the oil industry when work-over operations in low producing and abandoned wells are more common than new prospects, the best methods must be utilized together to ensure that by-passed and lowly producing reservoirs (either due to failure of technicians or Compartmentalization) are restored to a state of productivity that yields maximum profit.

According to Ailin and Dongbo (2012), it is common knowledge amongst industry experts that reservoir flow properties control the amount of producible hydrocarbon from reservoirs and as such these factors (such as porosity,

$\triangle$ S. S. Bodunde

segunstevenbodunde@yahoo.com

P. A. Enikanselu

paenikanselu@futa.edu.ng

1 Department of Applied Geophysics, Federal University of Technology, Akure, Nigeria permeability, and saturation) are essential in making economic decisions on any potential or producing reservoir. According to the theme of the SPE International Conference in 2015 (Society of Petroleum Engineers 2015), for uncertainties in reservoir characterization to be reduced and recovery maximized, an integrated method is best used. Also, reservoir characterization integrates all available data to define the geometry and physical properties of reservoirs. Slatt and Mark (2002), opined that the challenges faced by independent operators in characterizing compartmentalized reservoirs could be overcome by selecting the right techniques which involve integrating the proper methods for characterizing such reservoirs. Petrophysics seems to be the most widely utilized method in characterizing reservoirs as it provides a direct means of determining reservoir properties. Utilizing only petrophysical analysis and seismic data separately in characterizing and determining producibility of reservoirs gives a fairly conclusive result. For a better understanding of how reservoir properties such as porosity and permeability vary with measured seismic properties such

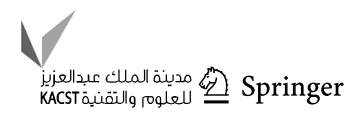


as acoustic impedance and velocity, rock physics should be used alongside Seismic models and measured reservoir properties (Mavko et al. 2009). This research thus takes all the above-stated opinions and facts into consideration and integrates seismic analysis with petrophysics and rock physics to define the structural properties, flow properties and reservoir geometry in general.

\section{Location and geology of the area}

The study area, SOKAB field is located in Niger Delta basin.

Klett et al. (1997) researched extensively and discovered that the Niger Delta stretches entirely around the Niger Delta Province. He further identified that the basin is primarily positionally referenced by the Gulf of Guinea. Doust et al. (1990) identified the satellite location of the entire extent of the Basin.

It was found to be between latitude $3^{\circ} \mathrm{E}$ and $9^{\circ} \mathrm{E}$ and longitude $4^{\circ} \mathrm{N}$ and $6^{\circ} \mathrm{N}$. In order of increasing depth, the Tertiary portion of Niger Delta Basin is primarily occupied by three orderly arranged beds of sedimentary rocks. They are the Benin, Agbada and Akata Formations. The Delta began its formation in a geologic time known as the late Jurassic (Lehner and De Ruiter 1977) and ended at another geologic time known as the middle Cretaceous. This formation occurred at a rift junction (Tuttle et al. 1999).

According to Doust et al. (1990), from a geologic time known as the Eocene till date, the delta has moved in a counterclockwise manner with respect to the North Pole in the south-west direction (prograde). Due to this movement, sedimentary deposits that describe a marine environment of deposition that are distinguishable from other sedimentary deposits were formed. These deposits have characteristics of water formed naturally close to the earth's surface and also of water formed at considerable depth extent. These marine characterized deposits form one of the largest regressive deltas in the world with an area of some $300,000 \mathrm{~km}^{2}$ (Kulke 1995). They are about 30-60 km wide, prograde southwestward 250 kilometers over oceanic crust into the Gulf of Guinea (Stacher 1995) and are defined by faults formed simultaneously with the rock and that occurred in response to variable rates of subsidence and sediment supply (Doust et al. 1990). Doust et al. (1990) described three of such marine depositional environments (depobelt) provinces based on the structure; the northern delta province, which overlies relatively shallow basement, has the oldest growth faults that generally rotational, evenly spaced, and increases their steepness seaward. The central delta province has depobelts with well-defined structures such as successively deeper
Fig. 1 Base map of the study Area

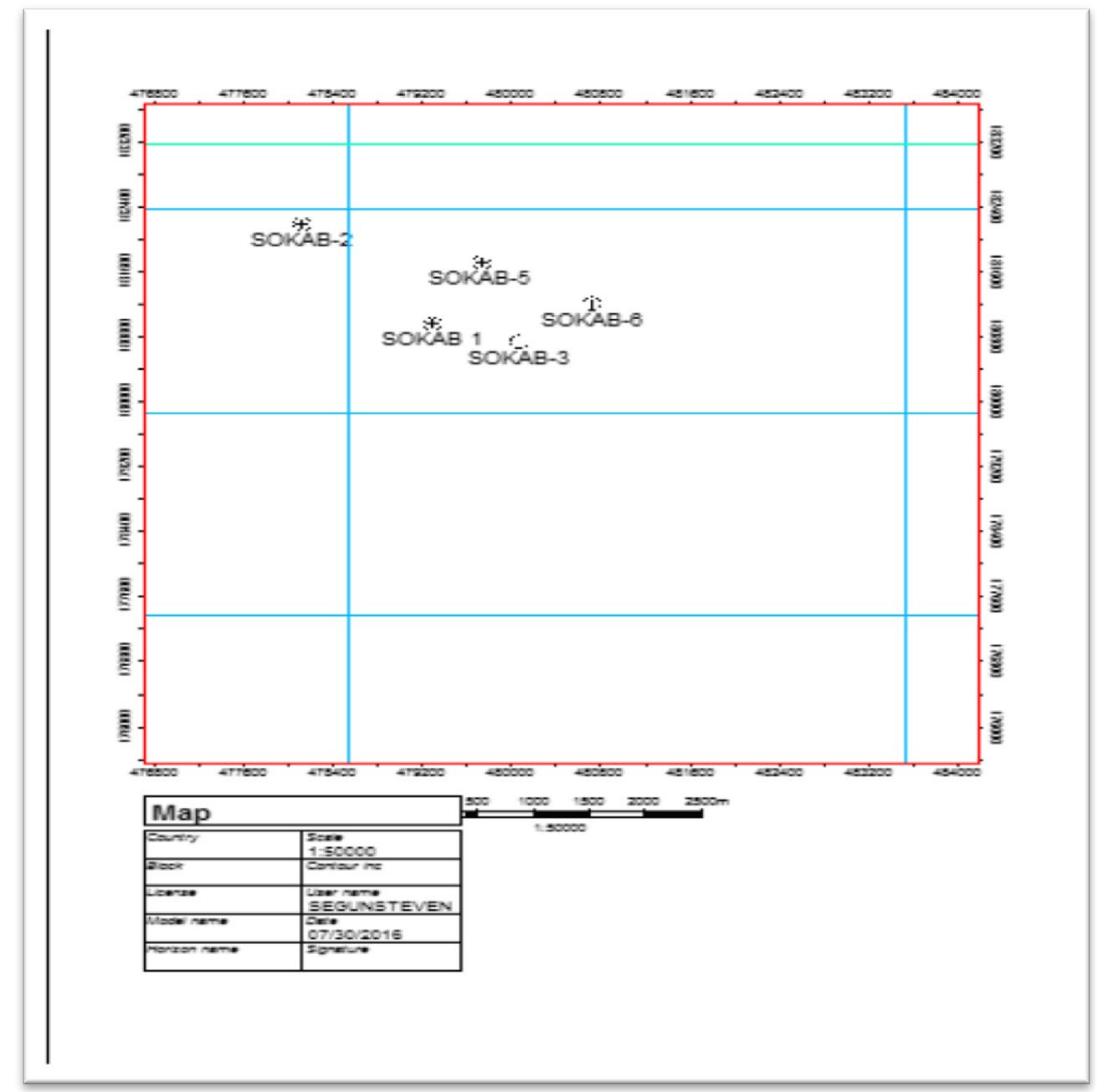


rollover crests that shift seaward for any given growth fault. Lastly, the distal delta province is the most structurally complex due to internal gravity tectonics on the modern continental slope.

\section{Materials and methods}

A dataset that comprised one volume of 3D-Seismic data and a suite of wireline logs from five wells (the logs include; gamma-ray logs, SP logs, resistivity logs, density logs, Sonic logs, and neutron logs.) in the study area as shown in Fig. 1 were utilized in carrying out this study.

All the analysis and interpretation carried out during this research work were done in three different categories with a common goal (to characterize the reservoir). These categories are:

1. Petrophysical analysis.

2. Seismic interpretation and modeling.

3. Rock physics cross-plot analysis and Gassmann's fluid substitution.

For the qualitative analysis, after the data was loaded, the gamma-ray log was used to delineate lithologies which were majorly an alternation of Sand and Shale. The fluid contents of the delineated lithologies were then determined using the resistivity log. The Sand units that were found to contain hydrocarbon were then correlated across the wells. Within this litho-unit, the contact points of the various fluids were identified using the porosity $\log$ s (density and neutron logs). The correlated sand units are shown in Fig. 2. The quantitative petrophysical analysis involved the calculation of various petrophysical parameters. Some of the key parameters calculated are listed below. Porosity was estimated using the expression;

$\phi=\frac{\rho_{\mathrm{ma}}-\rho_{\mathrm{b}}}{\rho_{\mathrm{ma}}-\rho_{\mathrm{f}}}$

where $\rho_{m a}$ is the grain or matrix density, $\rho_{f}$ is the density of the fluid or gas residing in the pore spaces and $\rho b$ is the bulk density.

The volume of shale was then calculated from the Dressler Atlas (1979) formula. This formula made use of the gamma-ray index.

$V_{\text {sh }}=0.083\left[2^{(3.7 * \operatorname{Igr})}-1.0\right]$

The effect of shale was then removed from the porosity and the effective porosity was generated. From water resistivity, water saturation was then calculated using Archie's (1942) equation;

$S_{\mathrm{w}}=\sqrt{\frac{a R_{\mathrm{W}}}{\phi^{m} R_{t}}}$

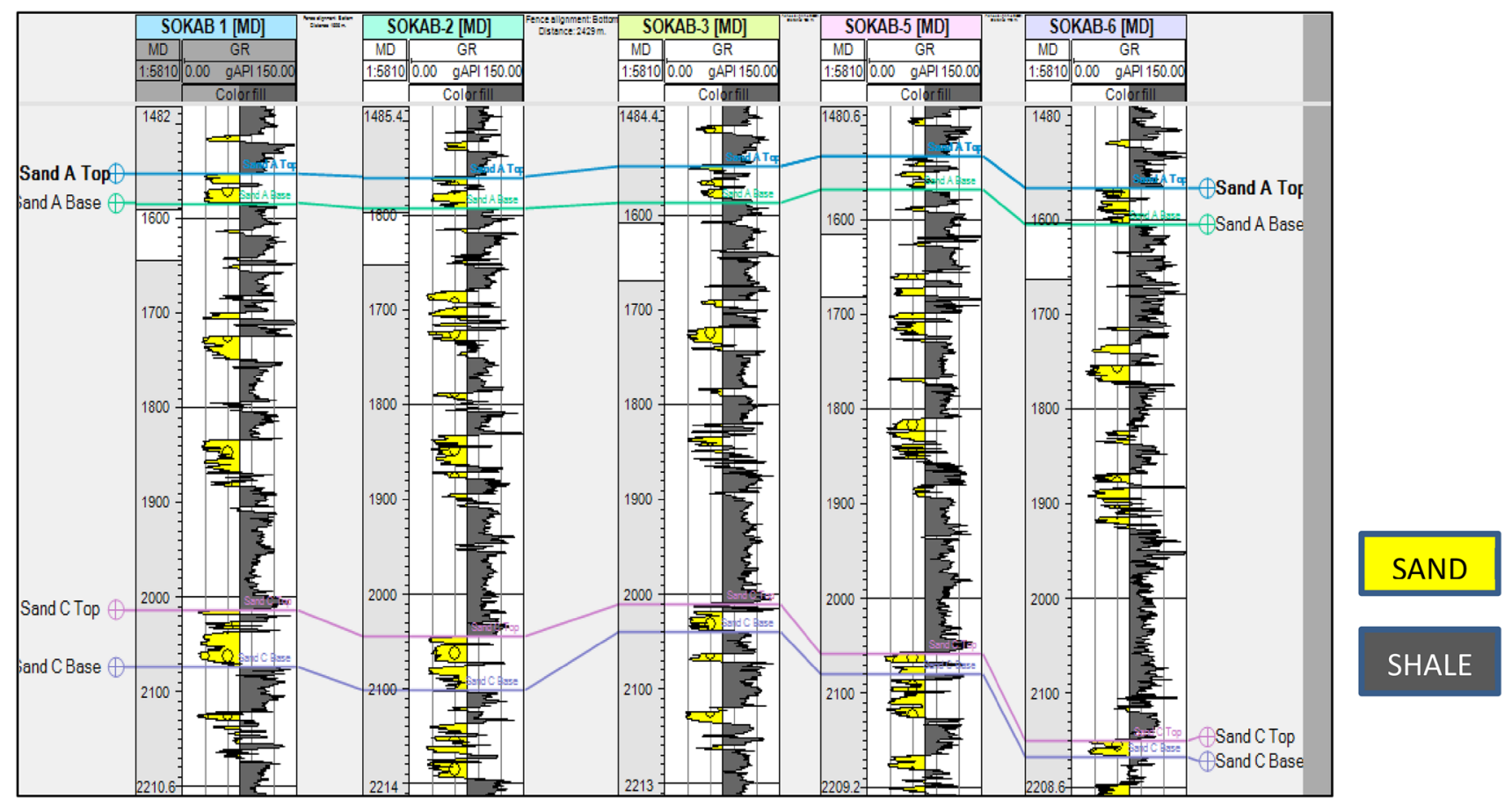

Fig. 2 Lithologic correlation of hydrocarbon bearing sands in SOKAB Field 


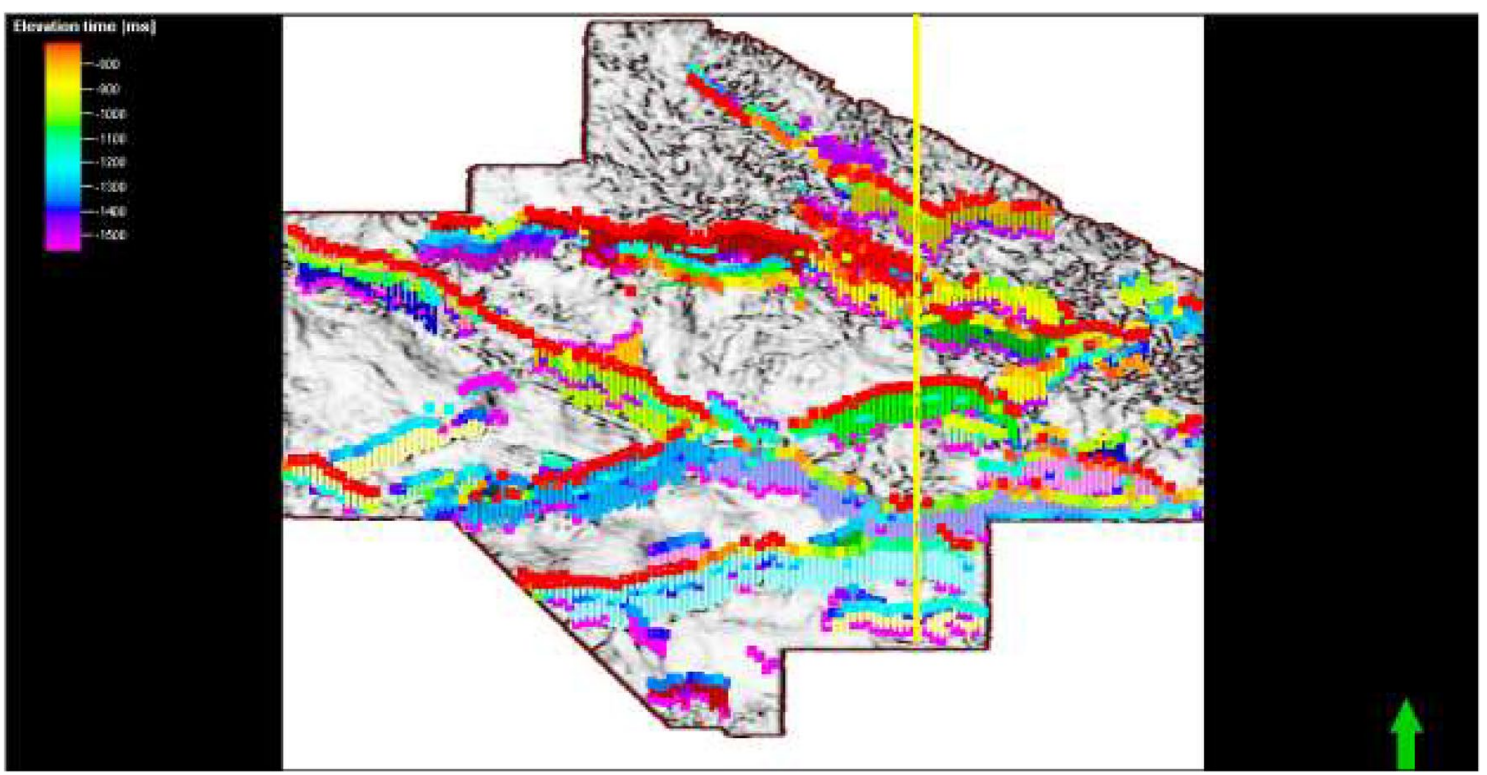

Fig. 3 variance edge showing the distribution of faults in SOKAB field

where $R_{\mathrm{t}}$ is the true formation resistivity as indicated on the ILD $\log$ and ' $a$ ' is the tortuosity factor. Hydrocarbon saturation $\left(S_{\mathrm{h}}\right.$ is the volume of pore space occupied by hydrocarbon) was then calculated using the expression;

$S_{\mathrm{h}}=1-S_{\mathrm{w}}$

The permeability was determined using the empirical relationship by Timur (1968):

$K^{1 / 2}=\frac{250 \Phi^{3}}{S_{\text {wirr }}}$.

On the seismic section, 43 faults were mapped on the Inlines and this included five major faults (Fig. 3 shows the fault distribution). The two hydrocarbon bearing sand units (Reservoir Sands A and B) correlated were then identified on the seismic section after a synthetic seismogram was generated to tie the seismic to the wells. They were then mapped across the Inline and X-line. Structural maps were then generated for these horizons. Porosity and permeability models were then generated for Sand A. The models were primarily used to show the distribution of the porosity and permeability values across the field. No further interpretation was based on the models as only a few numbers of wells were used to create the model for the entire reservoir.

Rock physics analysis was then carried out after the seismic and petrophysical analysis. The observed seismic properties were cross-plotted against the calculated petrophysical parameters to quality check the results of the petrophysical analysis and to further define the connectivity of the reservoirs. Four cross-plots were then generated for each reservoir across each well. The cross-plotted parameters on each well are listed below.

The results of the petrophysical analysis are presented in Table 1.

1. Primary velocity against porosity for mapping degree of cementation. The models utilized here are the friable sand and constant cement models. The 'cemented sand' or 'contact cement' model assumes that the porosity reduces owing to the uniform deposition of cement on the surface of the sand grains. Only a small amount of cement deposited at grain contacts is required to significantly increase the stiffness of the rock (Simm and Bacon 2009).

2. Velocity ratio against acoustic impedance for mapping fluid content of reservoirs.
Table 1 Average values of some of the petrophysical parameters estimated

\begin{tabular}{llllllllll}
\hline Reservoir & Thickness $(\mathrm{m})$ & $\phi(\%)$ & $V_{\mathrm{sh}}$ & $\Phi_{\text {eff }}(\%)$ & $R_{\mathrm{w}}(\Omega-\mathrm{m})$ & $S_{\mathrm{w}}(\%)$ & $S_{\mathrm{h}}(\%)$ & $S_{\mathrm{wirr}}$ & $K(\mathrm{md})$ \\
\hline Sand A & 35.4 & 24.8 & 0.12 & 22.6 & 0.091 & 43.78 & 56.22 & 0.093 & 2295 \\
Sand C & 36.4 & 23.2 & 0.0956 & 21.7 & 0.087 & 52.6 & 47.4 & 10.52 & 1754 \\
\hline
\end{tabular}


3. Primary velocity against secondary porosity for mapping lithology using the Greenberg-Castagna Sandstone trend.

4. Poisson ratio against volume of shale for mapping lithology.

The primary velocity and acoustic impedance were then calculated using the expressions;

$V_{\mathrm{p}}=\left(100,0000 / \mathrm{DT}_{\mathrm{C}}\right) * 0.3281$

$\mathrm{AI}=V_{p} * \rho^{b}$

where $V_{p}=$ primary velocity, $\mathrm{DT}_{\mathrm{c}}=$ compressional sonic $\log , \mathrm{AI}=$ acoustic impedance, $\rho_{b}=$ density from bulk density $\log$.

The secondary velocity $\left(V_{\mathrm{s}}\right)$ was generated using Greenberg and Castagna (1992) relation for sandstones.

$V_{\mathrm{s}}=0.8042 V_{\mathrm{p}}-0.8559$

\section{Fluid substitution}

To observe the change in seismic velocities (Compressional and shear) and density, Gassmann's equations were applied. Modeling the changes in these seismic properties are possible primarily due to the huge sensitivity of the bulk modulus to saturation changes. According to petrowiki.org (Petrowiki 2016) the bulk volume deformation produced by a passing seismic wave results in a pore volume change and causes a pressure increase of pore fluid (water). This has the effect of stiffening the rock and increasing the bulk modulus. Shear deformation usually does not produce pore volume change, and differing pore fluids often do not affect shear modulus. Below are the Gassmann equations.

$K_{\mathrm{s}}=K_{\mathrm{d}}+K_{\mathrm{d}}$,

$\Delta K_{\mathrm{d}}=\frac{K_{0}\left(1-\frac{K_{\mathrm{d}}}{K_{0}}\right)}{1-\phi-\frac{K_{\mathrm{d}}}{K_{0}}+\phi \frac{K_{0}}{K_{\mathrm{f}}}}$

$\mu_{s}=\mu_{d}$.

\section{Results and discussion}

The results from the petrophysical analysis, seismic interpretation, and rock physics cross-plot analysis are displayed below:

The qualitative petrophysical analysis resulted in the identification of two hydrocarbon bearing sands. The results of the quantitative analysis are shown in Table 1 . The analysis showed that the sands were hydrocarbon bearing with good pore interconnectivity and sufficient hydrocarbon saturation for production with total porosity above $23 \%$ and permeability above $1500 \mathrm{md}$.

From the seismic interpretation, 43 faults were mapped. Using a synthetic seismogram, seismic to well tie was done and the horizons corresponding to the two reservoirs delineated across the five wells were identified and mapped. Time and depth structural maps were then produced for both horizons (as shown in Figs. 4, 5). It could be observed that the wells are located around the major fault as it could be serving as a trapping mechanism.

Porosity and permeability models estimated across Sand A helped to show the distribution of these parameters in the reservoir across the five wells. From the porosity model, it was observed that the porosity ranges from 14 to $31 \%$ and this corresponded to a large extent with the range of porosity values from the petrophysical analysis (11-33\%). Also, the average porosity from the model was seen to be $24 \%$ while that from the petrophysical analysis was seen to be $24 \%$ (Figs. 6, 7).

The rock physics cross-plots were utilized in delineating lithology, fluid prediction and also to give an insight into the degree of cementation within the reservoirs.

For lithology identification, the Greenberg-Castagna Sandstone trend-line was used. From Fig. $8\left(V_{\mathrm{p}}-V_{\mathrm{s}}\right.$ crossplot), it could be observed that a cluster of the points aligned with the GC-Sandstone trend line and this indicated that a vast portion of the reservoir rock is sandstone.

On the $V_{\mathrm{p}}$-porosity cross-plot (Fig. 9), an approximately equal amount of the points could be observed to cluster both beneath the friable model and the constant cement model with the later indicating that they are more cemented compared to the upper and lower portions of the reservoir. On the color scale, they range from yellow to brown and also from dark blue to light blue. They occupy a range of depth from about 1550 to $1580 \mathrm{~m}$.

The fluid substitution carried out using Rokdoc involved draining the reservoir and then filling it with $80 \%$ hydrocarbon and $20 \%$ brine. This was also done with $20 \%$ hydrocarbon and $80 \%$ brine. From the plot of the dry rock bulk modulus against porosity, the stiffness of the rocks was predicted. The sands were observed to fall between the lower Reuss and upper Voigt bound which indicates a low level of cementation. Generally, on both reservoirs across all wells, the compressional velocity $\left(\mathrm{V}_{\mathrm{p}}\right)$ was observed to reduce with an increase of the brine saturation. The density behaved in a similar manner with little change observed in the shear wave velocity.

Below is a table showing the changes observed in the primary and secondary velocities, as well as the density when the saturation was changed from $20 \%$ hydrocarbon

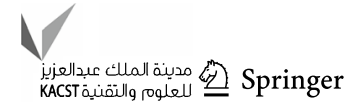


Fig. 4 Depth structural map of Sand A

Fig. 5 Depth structural map of Sand C
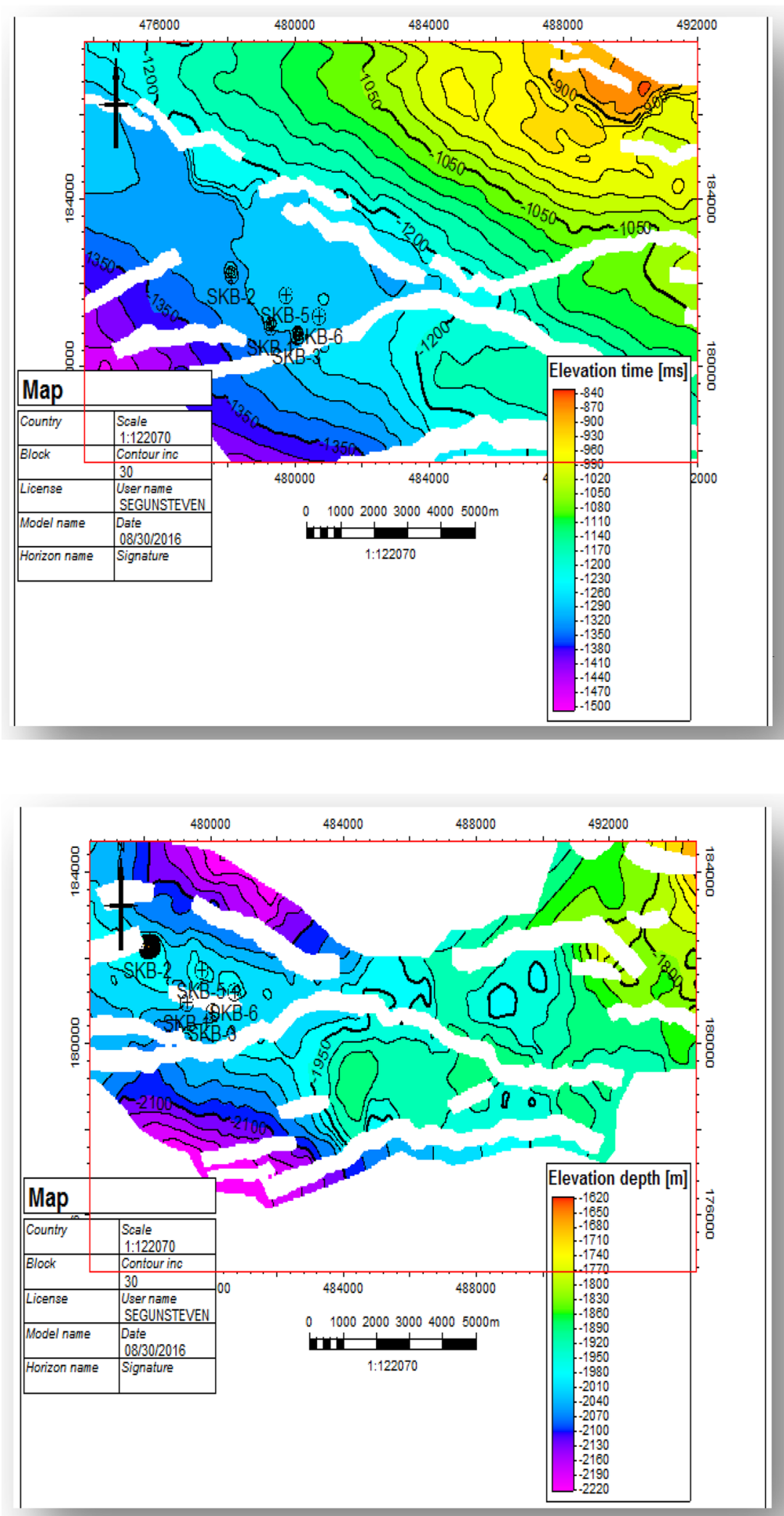

( $80 \%$ brine) to $80 \%$ hydrocarbon ( $20 \%$ brine). The secondary velocity was excluded due to its rather low change in signature as the saturation was changed. There was generally less than $1 \%$ change in the secondary velocity when the saturation changed from 20 to $80 \%$ (Table 2). 
Fig. 6 Gassmann's fluid substitution performed in SOKAB 6 Sand A (Sona)

Fig. 7 Gassmann's fluid substitution performed in SOKAB 6 Sand C (Danda)
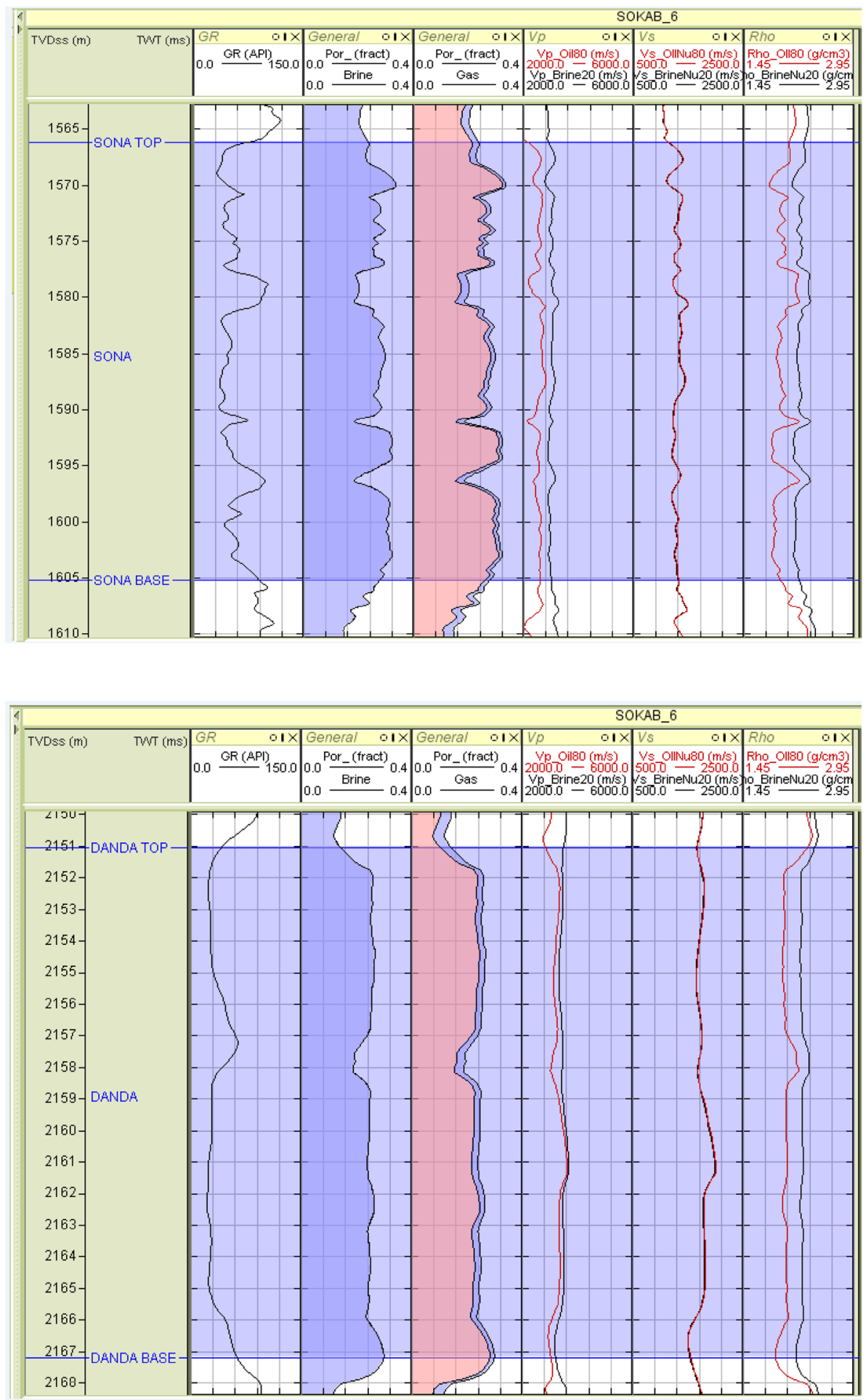

The velocity ratio-acoustic impedance cross-plot (Fig. 10) indicated an almost equal amount of brine (formation water) and hydrocarbon due to an approximately equal concentration of points on the brine and sand (hydrocarbon bearing) zones. The Poisson ratio-Shale volume cross-plot (Fig. 11) indicated that the reservoir had a low-shale content as most of the points on the cross-plot were colored blue which indicates an API value below 60 .

The same result obtained in this reservoir (Sand A) across well one was also obtained in other wells and also in Sand C. 
Fig. $8 V_{\mathrm{s}}$ against $V_{\mathrm{p}}$ cross-plot for Sand A across well one

Fig. $9 V_{\mathrm{p}}$ against porosity crossplot for Sand A across well one
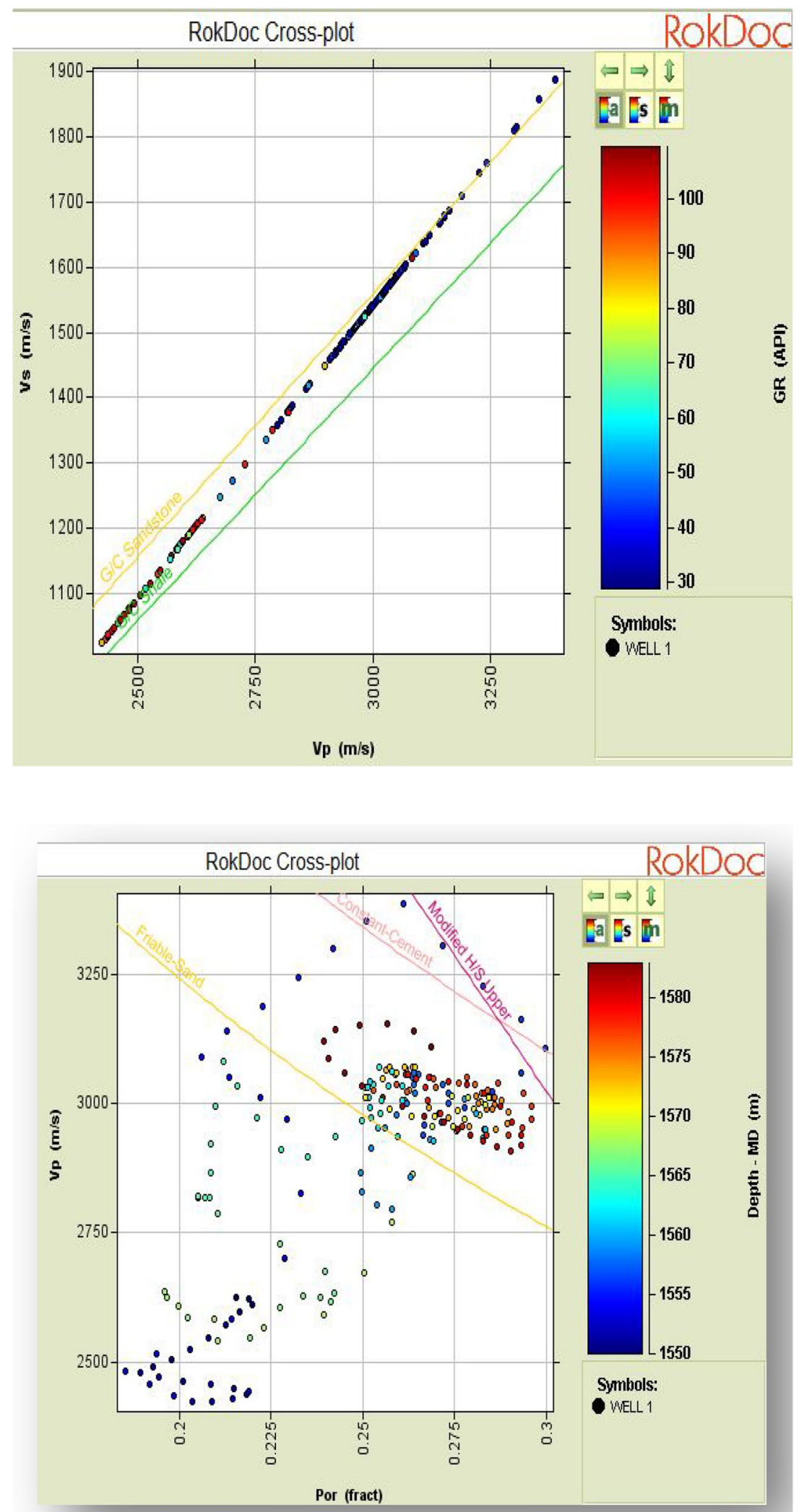
Table 2 Observed changes in velocities and density due to saturation change

\begin{tabular}{|c|c|c|c|c|c|c|c|}
\hline $\begin{array}{l}\text { SOKAB } 6 \\
\text { (Sand A) }\end{array}$ & Depth (m) & $\begin{array}{l}V_{\mathrm{p}}(20 \% \text { hydrocar- } \\
\text { bon saturation) }\end{array}$ & $\begin{array}{l}V_{\mathrm{p}}(80 \% \text { hydrocar- } \\
\text { bon saturation) }\end{array}$ & $\%$ Change & $\begin{array}{l}\text { Rho ( } 20 \% \text { hydrocar- } \\
\text { bon saturation) }\end{array}$ & $\begin{array}{l}\text { Rho ( } 80 \% \text { hydrocar- } \\
\text { bon saturation) }\end{array}$ & $\%$ Change \\
\hline 1 & 1570 & 2803 & 2419 & 13.67 & 2.106 & 1.792 & 14.91 \\
\hline 2 & 1580 & 3143 & 2463 & 21.64 & 2.335 & 2.174 & 6.9 \\
\hline 3 & 1590 & 2927 & 2456 & 16.09 & 2.196 & 1.940 & 11.66 \\
\hline $\begin{array}{l}\text { SOKAB } 6 \\
\text { (Sand C) }\end{array}$ & Depth (m) & $V_{\mathrm{p}}(20 \%$ HC Sat $)$ & $V_{\mathrm{p}}(80 \%$ HC Sat $)$ & $\%$ Change & Rho (20\% HC Sat) & Rho ( $80 \%$ HC Sat) & $\%$ Change \\
\hline 1 & 2155 & 3324 & 3136 & 5.66 & 2.222 & 1.984 & 10.71 \\
\hline 2 & 2165 & 3489 & 3340 & 4.27 & 2.255 & 2.038 & 9.62 \\
\hline $\begin{array}{l}\text { SOKAB } 5 \\
\text { (Sand A) }\end{array}$ & Depth (m) & $V_{\mathrm{p}}(20 \%$ HC Sat $)$ & $V_{\mathrm{p}}(80 \%$ HC Sat $)$ & $\%$ Change & Rho (20\% HC Sat) & Rho (80\% HC Sat) & $\%$ Change \\
\hline 1 & 1540 & 3104 & 2940 & 5.28 & 2.285 & 2.231 & 2.36 \\
\hline 2 & 1550 & 2871 & 2682 & 6.58 & 2.228 & 2.166 & 2.78 \\
\hline 3 & 1560 & 3372 & 3229 & 4.24 & 2.349 & 2.305 & 1.87 \\
\hline $\begin{array}{l}\text { SOKAB } 5 \\
(\text { Sand C) }\end{array}$ & Depth (m) & $V_{\mathrm{p}}(20 \%$ HC Sat $)$ & $V_{\mathrm{p}}(80 \%$ HC Sat $)$ & $\%$ Change & Rho (20\% HC Sat) & Rho ( $80 \%$ HC Sat) & $\%$ Change \\
\hline 1 & 2060 & 3144 & 2983 & 5.12 & 2.294 & 2.242 & 2.27 \\
\hline 2 & 2070 & 3496 & 3361 & 3.86 & 2.379 & 2.339 & 1.68 \\
\hline 3 & 2080 & 3422 & 3282 & 4.09 & 2.361 & 2.319 & 1.78 \\
\hline
\end{tabular}

Fig. 10 Velocity ratio against acoustic impedance cross-plot for Sand A across well one

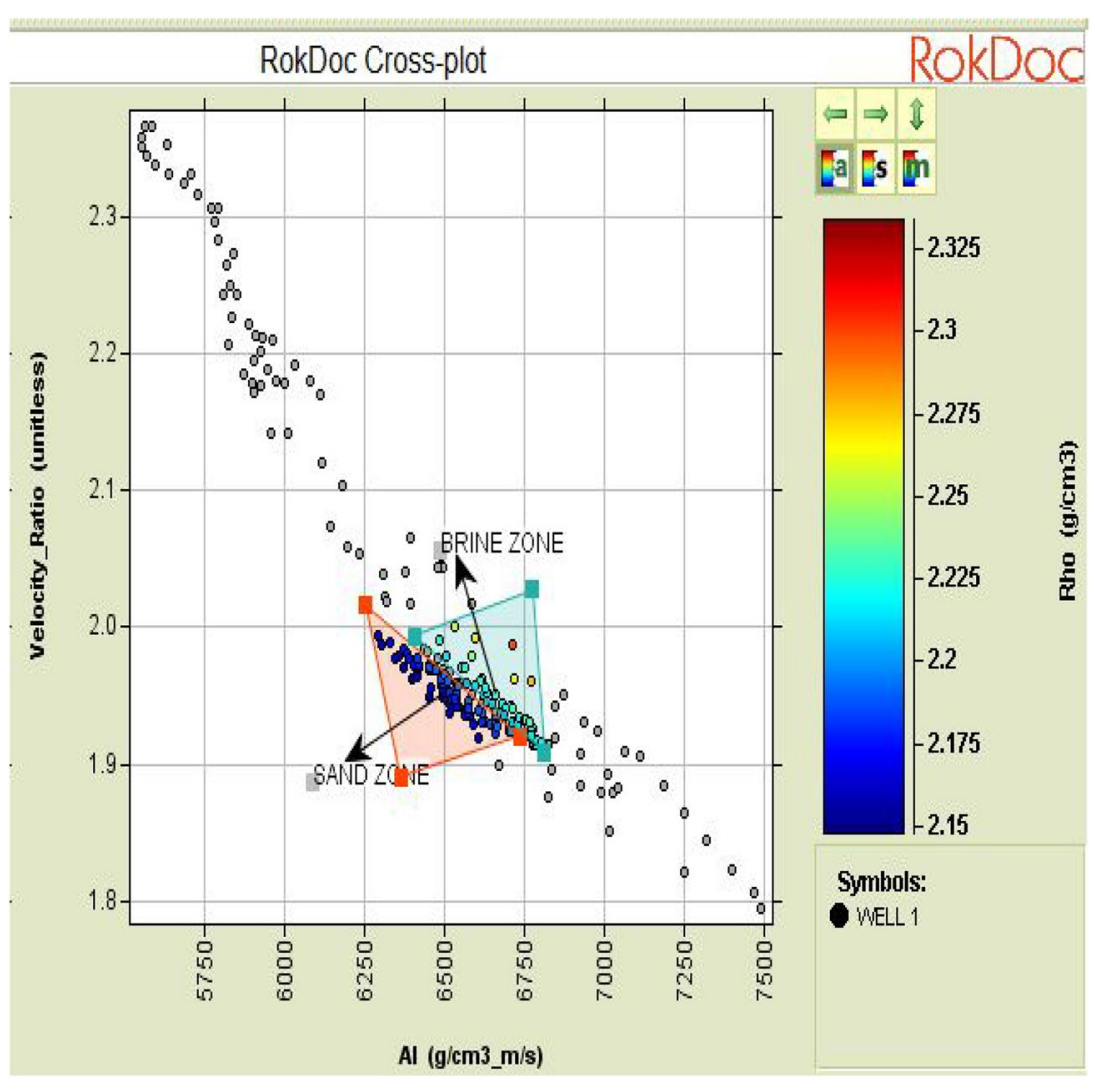


Fig. 11 Poisson's Ratio against Shale volume for Sand A across well one

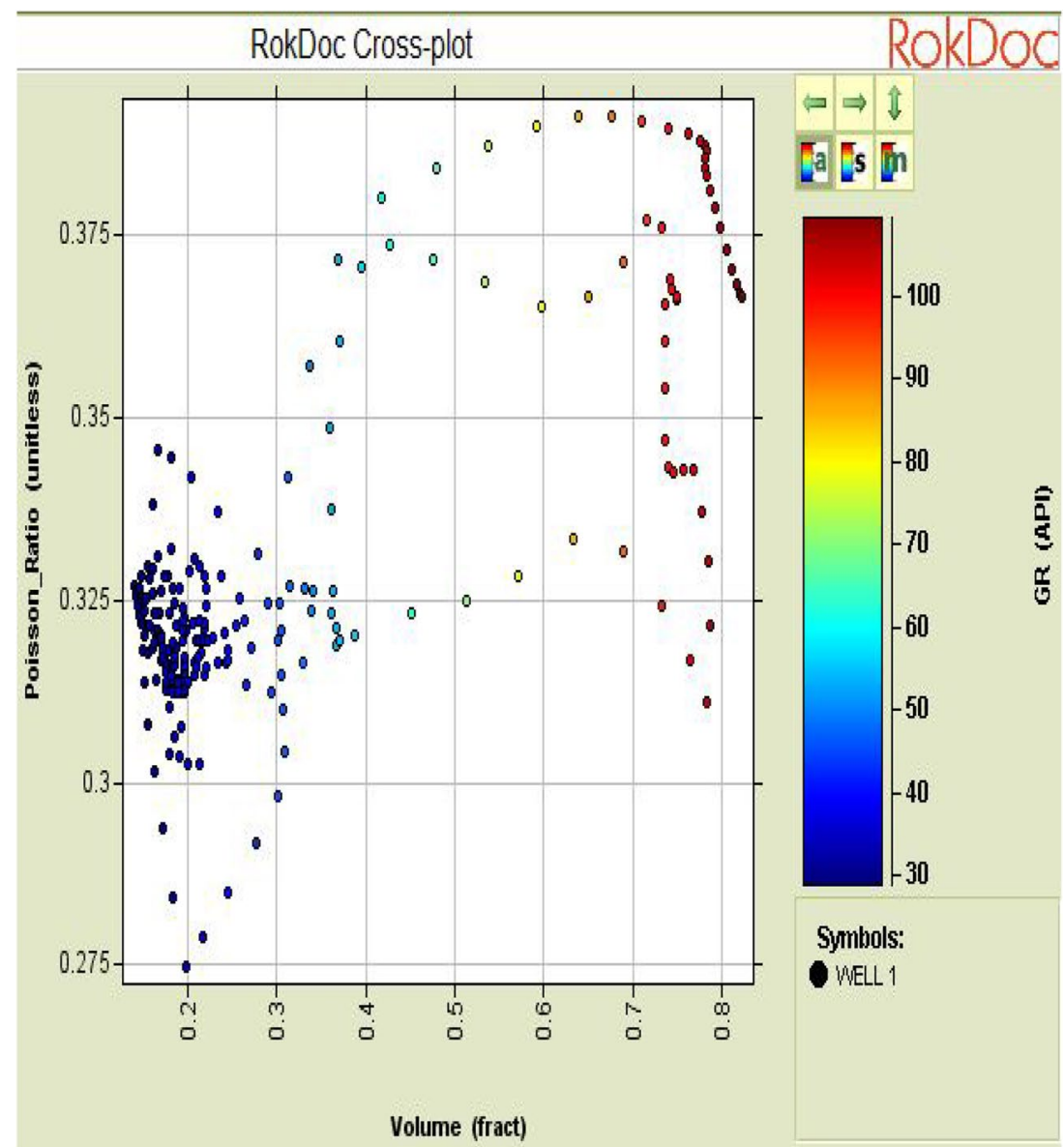

\section{Conclusion}

- This research highlighted the advantage of utilizing an integrated method in reservoir characterization. Since all methods define different properties of the reservoir, it is best to utilize an integrated method in order that all properties of the reservoir that are critical to determining their producibility are properly defined.

- The results from the Petrophysical analysis and Seismic interpretation and modeling were successfully quality checked with the use of rock-physics cross-plots. The reservoirs were found to be highly productive due to their good effective pore connectivity properties. (Average $\Phi_{\text {effective }}=23 \% \& 22 \%$ and Average $K_{\text {average }}=1754 \mathrm{md} \&$ $2295 \mathrm{md}$ for Sand A and B, respectively.)

- The Rock Physics analysis aided in the generation of missing data such as the shear velocity and also confirmed that the research work was carried out accurately (i.e., the petrophysical analysis was highly accurate in defining the reservoir properties). Furthermore, it showed that the lithologies within the reservoir were partially cemented (the lower portion) and poorly compacted which indicates a huge possibility of compartmentalization and brittle fracturing within the reservoir.
- Sokab 6 was found to possess the most potential for hydrocarbon production due to its pore properties (Average $\Phi$ effective $=24 \% \& 25.5 \%$ and $K_{\text {average }}=3209 \mathrm{md} \&$ $3439 \mathrm{md}$ in reservoirs A and C). Also, the pore connectivity across the wells was found to generally increase Northwards in the North-West portion of the field. It is thus advisable to carry further exploration activities in that part of the field for more prospects to be identified.

Open Access This article is distributed under the terms of the Creative Commons Attribution 4.0 International License (http://creativeco mmons.org/licenses/by/4.0/), which permits unrestricted use, distribution, and reproduction in any medium, provided you give appropriate credit to the original author(s) and the source, provide a link to the Creative Commons license, and indicate if changes were made.

\section{References}

Ailin J, Dongbo H (2012) Advances and the challenges of reservoir characterization: a review of the current state-of-the-art earth sciences. J Earth Sci. https://doi.org/10.5772/26404

Archie G (1942) The electrical resistivity log as an aid in determining some reservoir characteristics. Trans AIME 146:54-62 
Doust H, Omatsola E, Edwards JD, Santogrossi PA (1990) Divergent/ passive margin basins, AAPG memoir 48 Tulsa, American Association of Petroleum Geologists, p 239-248

Dresser Atlas (1979) Log interpretation charts. Dresser Industries, Inc., Houston, p 107

Greenberg ML, Castagna JP (1992) Shear wave velocity estimation in porous rocks: theoretical formulation, preliminary verification and applications. Geophys Prospect 40:195-209

Klett TR, Ahlbrandt TS, Schmoker JW, Dolton JL (1997) Ranking of the world's oil and gas provinces by known petroleum volumes: U.S Geological Survey Open file Report, pp 97-463

Kulke H (1995) Regional petroleum geology of the world. Part II: Africa, America, Australia and Antarctica: Berlin, Gebrüder Borntraeger, p 143-172

Lehner P, De Ruiter PAC (1977) Structural history of Atlantic margin of Africa. Am Assoc Petroleum Geol Bull 61:961-981

Mavko G, Tapan M, Dvorkin J (2009) The Rock Physics handbook, 2 edn. Cambridge University Press, NewYork

Petrowiki (2016) Gassmann's fluid substitution equation. Society of Petroleum International. https://petrowiki.org/ Gassmann\%2Cs_equation_for_fluid_substitution

Simm R, Bacon M (2009) Seismic amplitude: an interpreter's handbook. Cambridge University Press, New York
Slatt R, Mark S (2002) Practical reservoir characterization for the independent operator, computer technology for comprehensive reservoir characterization: Petroleum Technology Transfer Council, pp 512-514

Society of Petroleum Engineers (2015) Annual international conference preview. http://www.spe.org/events/rcsc

Stacher P (1995) Present understanding of the Niger Delta hydrocarbon habitat, in, Oti, M.N., and Postma

Timur A (1968) An investigation of permeability, porosity, and residual water saturation relationships for sandstone reservoirs. Log Analyst 9:8-17

Tuttle LW, Brownfield EM, Charpentier RR (1999) Tertiary Niger Delta (Akata-Agbada) Petroleum System (No. 701901), Niger Delta Province, Nigeria, Cameroon, and Equatorial Guinea, Africa. U.S Geological Survey Open file Report Open-File Report 99-50- $\mathrm{H}$

Publisher's Note Springer Nature remains neutral with regard to jurisdictional claims in published maps and institutional affiliations. 